
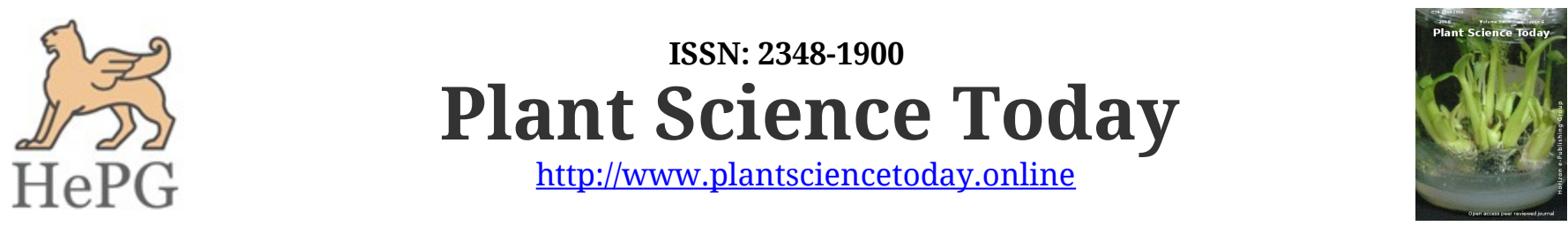

OPEN ACCESS

Research Article

\title{
Differential effects of plant growth promoting rhizobacteria on chilli (Capsicum annuum L.) seedling under cadmium and lead stress
}

\author{
A K Pal, A Chakraborty, C Sengupta \\ Microbiology Research Laboratory, Department of Botany, University of Kalyani, Kalyani 741235, West Bengal, India
}

\section{Article history}

Received: 17 August 2018

Accepted: 20 September 2018

Published: 12 November 2018

\section{Editor}

Dr. Radka Podlipná, Institute of Experimental Botany, The Czech Academy of Sciences, Prague,

Czech Republic

\section{Publisher}

Horizon e-Publishing Group

\author{
*Correspondence \\ Chandan Sengupta \\ \.handansenguptaku@gmail.com
}

\begin{abstract}
Rapidly increasing worldwide industrialization has led to many environmental problems by the liberation of pollutants such as heavy metals. Day by day increasing metal contamination in soil and water can be best coped by the interaction of potential plant growth promoting rhizobacteria for plant growth. The effect of plant growth promoting rhizobacteria (PGPR) treatment on growth of chilli plant subjected to heavy metal stress was evaluated. Growth of chilli plant was examined with inoculation of two isolated PGPR (Lysinibacillus varians and Pseudomonas putida) under cadmium (30 ppm), lead (150 ppm) and the combination of heavy metal $(\mathrm{Cd}+\mathrm{Pb})$ stress condition. Among these two bacteria $L$. varians produced slightly better plant growth enhancement. Different growth parameters of chilli plants were reduced under heavy metal stress. Whereas, $\mathrm{Cd}$ and Pb tolerant PGPR inoculation, in root associated soil, enhanced plant growth development under test heavy metal contaminated soil. So, these PGPRs may easily be used as bio-fertilizers which will nullify the adverse effect of heavy metal on plant growth.
\end{abstract}

\section{Keywords}

Plant growth; plant growth promoting rhizobacteria; cadmium and lead stress; Lysinibacillus varians; Pseudomonas putida

\section{Citation}

Pal A K, Chakraborty A, Sengupta C. Differential effects of plant growth promoting rhizobacteria on chilli (Capsicum annuum L.) seedling under cadmium and lead stress. Plant Science Today 2018;5(4):182-190. https://dx.doi.org/10.14719/pst.2018.5.4.419

Copyright: (c) Pal et al. (2018). This is an open-access article distributed under the terms of the Creative Commons Attribution License, which permits unrestricted use, distribution, and reproduction in any medium, provided the original author and source are credited (https://creativecommons.org/licenses/by/4.0/).

Indexing: Plant Science Today is covered by Scopus, CAS, AGRIS, CABI, Google Scholar, etc. Full list at http://www.plantsciencetoday.online

\section{Introduction}

Heavy metals are non-degradable and eventually contaminate the environment and plants (1) causing serious human health hazards (2). The heavy metals with deadly in nature include zinc (Zn), chromium (Cr), arsenic (As), cadmium (Cd), copper $(\mathrm{Cu})$, mercury $(\mathrm{Hg})$, nickel $(\mathrm{Ni})$ and lead $(\mathrm{Pb})$ (3). Some of the heavy metals are used by plants as micronutrients but the unbalanced exposure of heavy metals in nature is injurious to the majority of plants. Elevated levels of heavy metal ions in the environment cause different morphological and biochemical alteration in plant such as inhibition of 
seed germination, underdeveloped root-shoot growth, induce leaf chlorosis, decreased photosynthesis, increased oxidative stress, initiation of senescence, etc $(4,5)$. Heavy metal accumulation in plant body subsequently transferred to higher trophic level and responsible for declining immunological defences, intrauterine growth retardation, and disabilities associated with malnutrition and upper gastrointestinal cancer in humans (6-8). Heavy metals especially $\mathrm{Cd}$ and $\mathrm{Pb}$ are of most important apprehension throughout the industrialized world through the soil contamination (9). $\mathrm{Cd}$ and $\mathrm{Pb}$ pollution not only hamper plant quality and yield but also cause disturbances in the composition, size, and activity of the microbial community (10). Rhizospheric region may have many types of active groups of bacteria which are effective for plant growth, termed as "PGPR" (Plant Growth Promoting Rhizobacteria) (11, 12). PGPRs are useful for plant growth enhancement via two mechanisms first is the direct mechanisms such as nitrogen fixation, phosphate solubilization, growth-regulating agents production, increasing availability of nutrients to the plant, production of plant hormones and vitamins such as gibberellin, cytokinin and auxin, and the second is the indirect mechanisms includes antibiotics synthesis, make iron available, competing with root-inhabiting species $(13,14)$ causing systemic resistance in the plant, production of $\mathrm{HCN}$, and promoting plant resistance in stress conditions caused by non-living factors $(13,14) \mathrm{Cd}$ and $\mathrm{Pb}$ tolerant bacteria develop few survival strategies such as intracellular bioaccumulation and biosorption $(15,16)$ that play important roles in the mobilization or immobilization of different heavy metals into plant body $(15,17-20)$. Plants and PGPRs in association can improve biomass production and tolerance of the plants to heavy metals $(18,20,21)$. This study was designed to investigate the effect of cadmium and lead tolerant PGPRs on the growth of Capsicum annuum $\mathrm{L}$. under $\mathrm{Cd}$ and $\mathrm{Pb}$ contaminated condition.

\section{Materials and Methods}

\section{Collection of Bacteria}

Two potent cadmium and lead tolerant plant growth promoting rhizobacteria were isolated, characterized and identified previously as Lysinibacillus varians (NCBI GenBank acc. no. MG976681) and Pseudomonas putida (GenBank acc. no. MG976684) for this research work.

\section{Isolation of Rhizospheric Bacteria}

Rhizospheric bacteria were isolated from soil samples of Titagarh, West Bengal, India by standard soil dilution plate count technique using nutrient agar as supporting medium [peptone $-5 \mathrm{~g}$, beef extract $-3 \mathrm{~g}$, agar $-15 \mathrm{~g}$, $\mathrm{NaCl}-5 \mathrm{~g}, \mathrm{pH}-7.0$, Water $-1 \mathrm{~L}]$.

\section{Determination of minimum inhibitory concentration (MIC) of cadmium (Cd) and lead $(\mathrm{Pb})$ on the isolated bacterial strains}

Bacterial isolates were inoculated on nutrient agar medium added with different concentrations (such as $50,100,150, \ldots .600 \mathrm{ppm}$ ) of cadmium or lead. After $48 \mathrm{~h}$ of incubation at $37 \pm 2^{\circ} \mathrm{C}$, observation of bacterial growth, if any, were recorded.

\section{Characterization of Bacteria}

The Cd resistant bacterial isolates were characterized by their morphological, cultural, staining and biochemical properties. Morphological characters include colour, elevation and edge of the colony were studied. Gram nature of each isolates was ascertained by using crystal violet and safranin staining following the standard method.

\section{Biochemical Characterization}

For biochemical characterization of isolated bacteria, standard tests such as Catalase test, Amylase test, and Gelatine hydrolysis test were performed.

\section{Determination of plant growth promoting (PGPR) ability of the isolated bacteria}

Plant growth promoting ability of the bacterial isolates were estimated by standard technique as depicted below.

\section{Detection for the IAA Production}

Bacterial isolates were inoculated in the Luria Bertani (LB) medium (tryptone $-10 \mathrm{~g}$, Yeast extract - $5 \mathrm{~g}, \mathrm{NaCl}-10 \mathrm{~g}$, distilled water - $1 \mathrm{~L}, \mathrm{pH}-7.0)$ supplemented with L-tryptophan $(0.2 \%)$ for $24 \mathrm{~h}$ at $28^{\circ} \mathrm{C}$ on rotary shaker, centrifuged at $10000 \mathrm{rpm}$ for $15 \mathrm{~min}$. Then $2 \mathrm{ml}$ of supernatant, 2-3 drops of O-phosphoric acid along with $4 \mathrm{ml}$ of Salkowski's reagent (100 $\mathrm{ml}$ of $35 \%$ Perchloric acid and freshly prepared $2 \mathrm{ml}$ of $0.5 \% \mathrm{M} \mathrm{FeCl}_{3}$ solution) were mixed. Absorbance was recorded at $530 \mathrm{~nm}$ after 30 min of incubation in dark room. Quantity of auxin was calculated from the standard curve using indole acetic acid as standard (10-100 $\mu \mathrm{g}$ $/ \mathrm{ml}$ ).

\section{Detection of Phosphate solubilizing ability}

Phosphate solubilizing ability was determined from the isolated bacteria by standard microbiological technique. The bacterial isolates were inoculated into the sterile Petri Dishes containing Pikovskaya's medium (HIMEDIA) and incubated for 2 - 3 days at $32 \pm 2^{\circ} \mathrm{C}$ after incubation, observed the hallow zone production around the colony for the positive result.

\section{Detection for the Ammonia production}

Each bacterial isolate was inoculated in the peptone water broth (peptone $-4 \mathrm{~g}$, Water - $1 \mathrm{~L}, \mathrm{pH}$ 
Table 1: Colony morphology of bacterial isolates, Gram nature, biochemical and PGPR confirmation tests

\begin{tabular}{|c|c|c|c|c|c|c|c|c|c|c|c|c|}
\hline \multirow{2}{*}{ 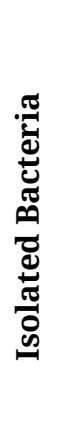 } & \multirow[b]{2}{*}{$\begin{array}{c}\text { Colony } \\
\text { morphology }\end{array}$} & \multirow[b]{2}{*}{$\begin{array}{l}\text { Gram } \\
\text { nature }\end{array}$} & \multicolumn{2}{|c|}{$\begin{array}{c}\text { Minimum } \\
\text { inhibitory } \\
\text { concentration } \\
\text { (ppm) }\end{array}$} & \multicolumn{3}{|c|}{$\begin{array}{c}\text { Biochemical } \\
\text { characterization }\end{array}$} & \multicolumn{5}{|c|}{ PGPR activity } \\
\hline & & & שี & త్ర & 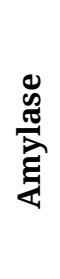 & 总 & 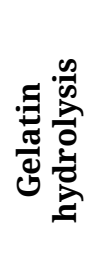 & 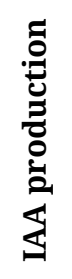 & 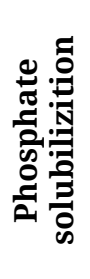 & 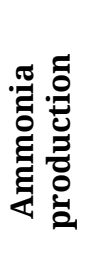 & 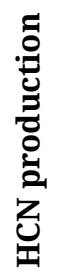 & 先 \\
\hline 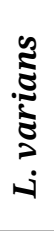 & $\begin{array}{l}\text { Creamy } \\
\text { yellow, } \\
\text { circular } \\
\text { serrated, } \\
\text { opaque } \\
\text { glossy }\end{array}$ & $\begin{array}{l}\text { Positive, } \\
\text { rod }\end{array}$ & 옴 & $\begin{array}{l}\circ \\
\text { ஜn }\end{array}$ & - & +++ & - & +++ & + & +++ & - & + \\
\hline 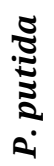 & $\begin{array}{l}\text { Creamy } \\
\text { white, } \\
\text { circular } \\
\text { entire glossy }\end{array}$ & $\begin{array}{l}\text { Negative, } \\
\text { rod }\end{array}$ & $\stackrel{\text { 음 }}{\rightarrow}$ & 요 & - & +++ & - & +++ & ++ & +++ & - & - \\
\hline
\end{tabular}

('+' or '-' sign indicate the positive or negative approach of the test. No of ‘+' sign denote the intensity of positive result of the respective tests)

Table 2: Survival ability of bacterial isolates in different soil ecological conditions

\begin{tabular}{|c|c|c|c|c|}
\hline \multirow{2}{*}{ Conditions } & \multicolumn{2}{|c|}{ L. varians } & \multicolumn{2}{|c|}{ P. putida } \\
\hline & 30 days & 60 days & 30 days & 60 days \\
\hline $50 \%$ water holding capacity & +++ & + & +++ & ++ \\
\hline Flood & +++ & + & +++ & ++ \\
\hline Salinity (5\%) & ++ & + & + & - \\
\hline Drought & ++ & + & ++ & - \\
\hline 10 ppm cadmium & +++ & + & +++ & ++ \\
\hline $100 \mathrm{ppm}$ lead & +++ & + & +++ & ++ \\
\hline
\end{tabular}

- 7.2) and incubated for 4 days in $37 \pm 2^{\circ} \mathrm{C}$. After incubation period, $1 \mathrm{ml}$ of Nessler's reagent was added to the tubes. Change of colour to deep yellow brown of the broth indicates the ability of each isolate for ammonia production.

\section{Detection for the HCN Production}

Bacterial isolates were inoculated by streaking on sterile King's B agar medium (proteose peptone 20 g, glycerol - 10 g, $\mathrm{K}_{2} \mathrm{HPO}_{4}-1.5 \mathrm{~g}, \mathrm{MgSO}_{4} .7 \mathrm{H}_{2} \mathrm{O}$ - 1.5 $\mathrm{g}$, agar - $20 \mathrm{~g}$, distilled water - $1 \mathrm{~L}, \mathrm{pH}-7.2$ ). Plates amended with $4.4 \mathrm{~g} / \mathrm{L}$ glycine. Whatman no.1 filter paper disc soaked in $0.5 \%$ picric acid and $2 \%$ $\mathrm{Na}_{2} \mathrm{CO}_{3}$ and placed on the lid of each Petri plate and sealed with paraffin. Incubate at $32 \pm 2^{\circ} \mathrm{C}$ for 4 days. Colour change of the filter paper from deep yellow to orange and finally to orange brown to dark brown was observed in comparison to the control.

\section{Growth on nitrogen free medium (Jensen's Medium)}

The bacteria isolates were inoculated into the sterile Petri plates containing Jensen's medium (sucrose - $20 \mathrm{~g}, \mathrm{~K}_{2} \mathrm{HPO}_{4}-1 \mathrm{~g}, \mathrm{MgSO}_{4}-0.5 \mathrm{~g}, \mathrm{NaCl}$ $0.5 \mathrm{~g}, \mathrm{FeSO}_{4}-0.1 \mathrm{~g}, \mathrm{Na}_{2} \mathrm{MoO}_{4}-0.005 \mathrm{~g}, \mathrm{CaCO}_{3}-2 \mathrm{~g}$, agar - $15 \mathrm{~g}$ in $1 \mathrm{~L}$ distilled water) and incubated for 2-3 days at $32 \pm 2^{\circ} \mathrm{C}$ after incubation, observed the colony for the positive result.

Determination of survivability of isolated PGPR under different soil condition

To determination of survivability of PGPR, they were inoculated in different soil conditions (e.g. drought, flood, 50\% water holding capacity, salinity, $\mathrm{Cd}$ and $\mathrm{Pb}$ treated conditions). $100 \mathrm{~g}$ of sterile soil were inoculated with $1 \mathrm{ml}$ of $24 \mathrm{~h}$ old nutrient broth culture of test bacteria. After 1 month interval bacterial colony was observed by standard soil dilution plate count technique. 


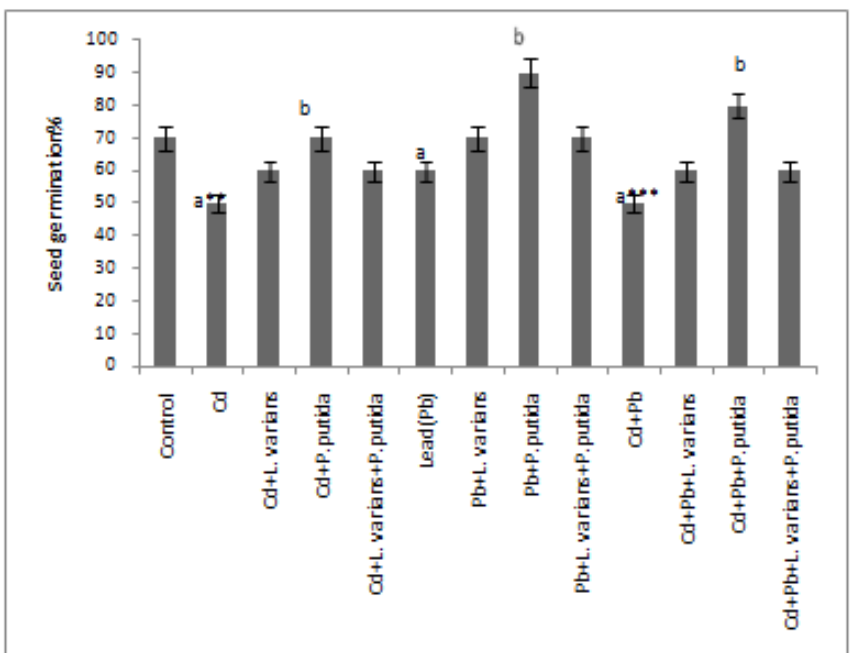

Fig.1. Seed germination after 1 week of exposure to heavy metals with PGPRs. Difference between control and respective heavy metal treated groups are denoted by lower case alphabet ' $a$ '. Asteric mark $(*)$ above the bars indicate significance level. Lower case alphabet ' $b$ ' indicates significant result at $p<0.05$ between heavy metal treated groups and PGPR inoculated respective heavy metal treated groups.

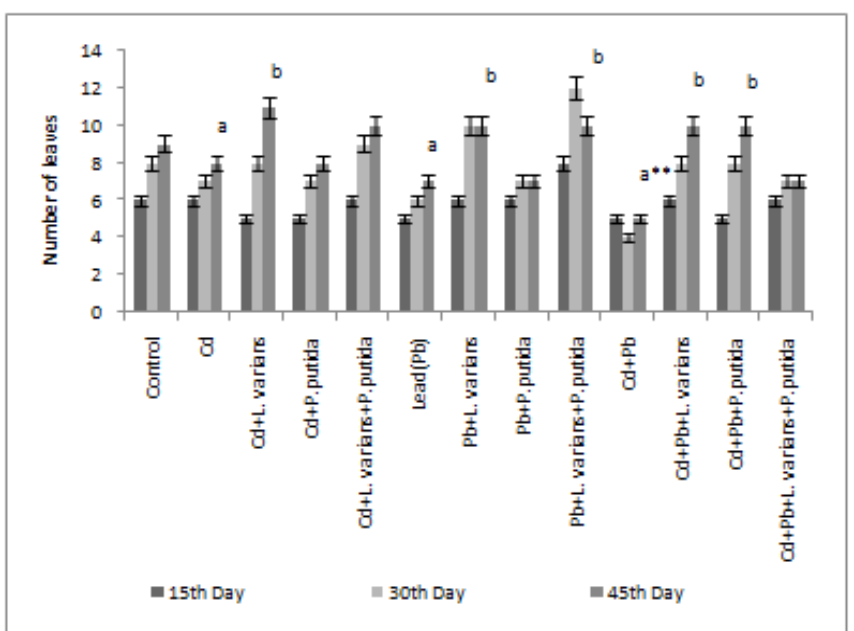

Fig. 3. Number of leaves/plant after 15 days interval upto 45 days of exposure to heavy metal enriched soil inoculating with PGPRs. Difference between control and respective heavy metal treated groups are denoted by lower case alphabet ' $a$ '. Asteric mark (*) above the bars indicate significance level. Lower case alphabet ' $b$ ' indicates significant result at $p<0.05$ between heavy metal treated groups and PGPR inoculated respective heavy metal treated groups.

\section{Exploitation of plant growth promoting rhizobacterial strains on growth and development of chilli (C. annuum) seedlings in heavy metal stress condition}

\section{Collection of seed}

Chilli (C. annuum) was used as plant model in this experiment. Chilli seeds were collected from Bidhan Chandra Krishi Viswavidyalaya, West Bengal, India.

\section{Determination of seed germination percentage}

The chilli seeds were surface sterilized by $0.1 \%$ $\mathrm{HgCl}_{2}$ for $3 \mathrm{~min}$ followed by several wash with

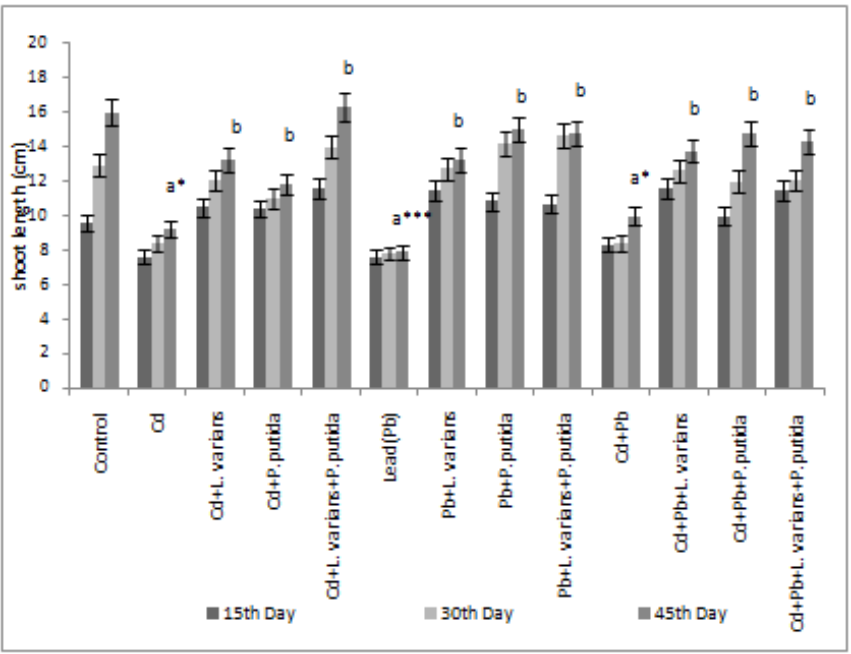

Fig. 2. Shoot length (cm) after 15 days interval upto 45 days of exposure to heavy metal enriched soil inoculating with PGPRs. Difference between control and respective heavy metal treated groups are denoted by lower case alphabet 'a'. Asteric mark $\left(^{*}\right)$ above the bars indicate significance level. Lower case alphabet 'b' indicates significant result at $p<0.05$ between heavy metal treated groups and PGPR inoculated respective heavy metal treated groups.

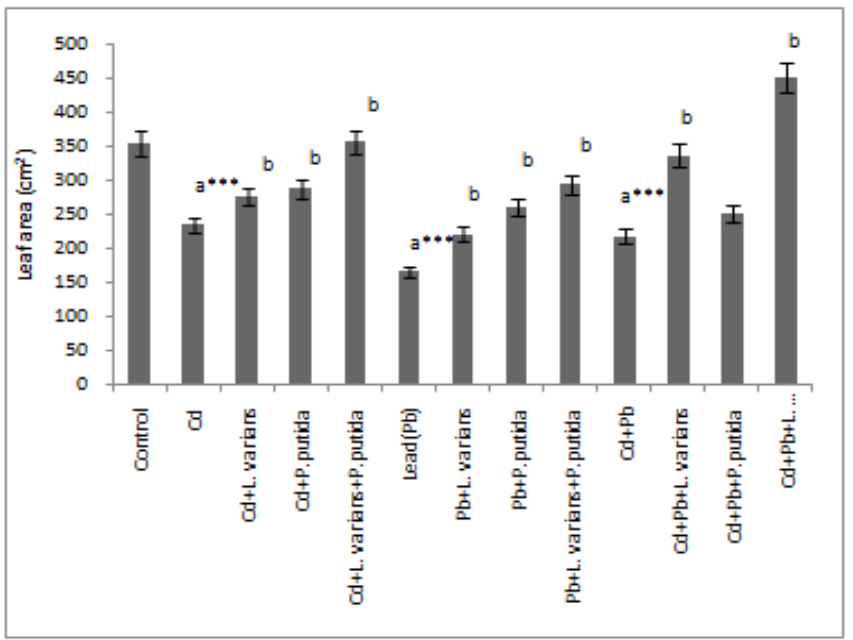

Fig. 4. Leaf area $\left(\mathrm{cm}^{2}\right)$ per plant after 45 days of exposure

to heavy metal enriched soil inoculating with PGPRs. Difference between control and respective heavy metal treated groups are denoted by lower case alphabet 'a'. Asteric mark $\left(^{*}\right)$ above the bars indicate significance level. Lower case alphabet ' $b$ ' indicates significant result at $p<0.05$ between heavy metal treated groups and PGPR inoculated respective heavy metal treated groups.

sterilized distilled water. After $24 \mathrm{~h}$, the seeds were placed on the sterile blotting paper containing 30 ppm of $\mathrm{Cd}, 150 \mathrm{ppm}$ of $\mathrm{Pb}$ or combination of $\mathrm{Cd}$ and $\mathrm{Pb}$ on petri plates with combination of isolated PGPRs ( $L$. varians and/or P. putida). Different experimental set-ups were as follows - Control, $\mathrm{Cd}$, $\mathrm{Cd}+$ L. varians, $\mathrm{Cd}+$ P. putida, $\mathrm{Cd}+$ L. varians $+P$. putida, $\mathrm{Pb}, \mathrm{Pb}+L$. varians, $\mathrm{Pb}+P$. putida, $\mathrm{Pb}+L$. varians $+P$. putida, $\mathrm{Cd}+\mathrm{Pb}, \mathrm{Cd}+\mathrm{Pb}+L$. varians, $\mathrm{Cd}+\mathrm{Pb}+$ P. putida, $\mathrm{Cd}+\mathrm{Pb}+$ L. varians + P. putida . In control sets the seeds were treated only with distilled water. Number of seed germination was recorded after $24 \mathrm{~h}$ intervals up to 7 days. 


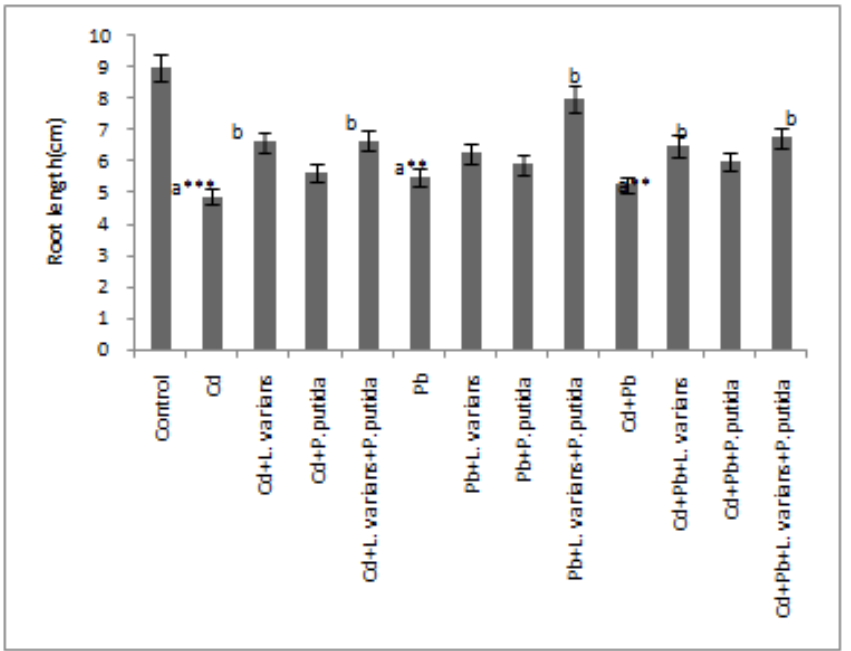

Fig. 5. Root length (cm) after 45 days of exposure to heavy metal enriched soil inoculating with PGPRs. Difference between control and respective heavy metal treated groups are denoted by lower case alphabet 'a'. Asteric mark $(*)$ above the bars indicate significance level. Lower case alphabet ' $\mathrm{b}$ ' indicates significant result at $p<0.05$ between heavy metal treated groups and PGPR inoculated respective heavy metal treated groups.

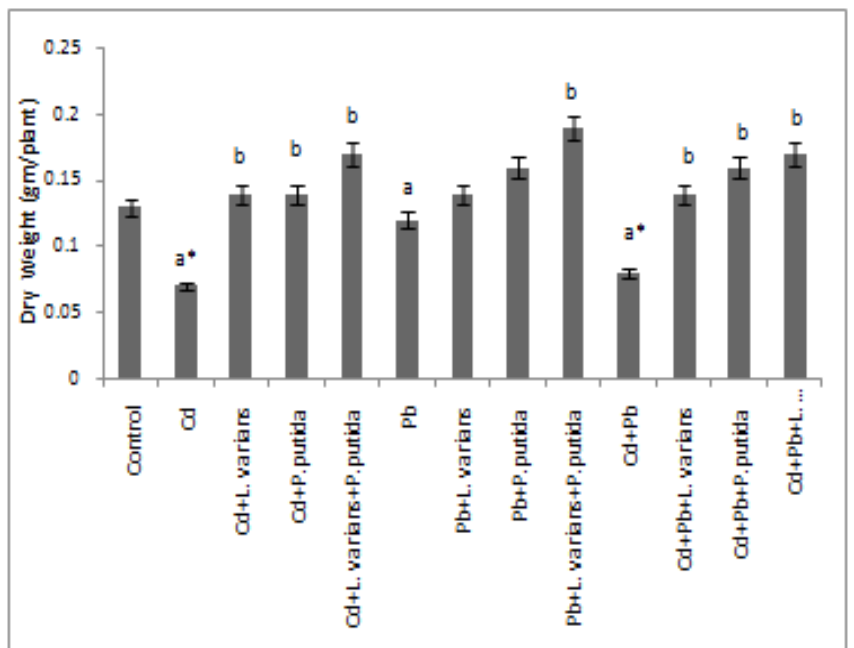

Fig. 7. Dry weight (gm/plant) of exposure to heavy metal enriched soil inoculating with PGPRs. Difference between control and respective heavy metal treated groups are denoted by lower case alphabet 'a'. Asteric mark $\left({ }^{*}\right)$ above the bars indicate significance level. Lower case alphabet ' $b$ ' indicates significant result at $p<0.05$ between heavy metal treated groups and PGPR inoculated respective heavy metal treated groups.

Germination percentage $=$ (Total no. of germinated seeds / Total no. of seeds) x 100 .

\section{Pot Experiments}

Pots for exploitation were prepared with sleeved soil and sand as on third depth of pot were filled with sand and upper remaining portion were filled with fine soil. Previously, used soil and sand were separately sterilized with autoclave at $15 \mathrm{lb}$ pressure for $1 \mathrm{~h}$. Chilli seeds were imbibed separately in two bacterial suspensions ( $L$. varians or $P$. putida) and in other set; both the bacteria were inoculated jointly during imbibitions of chilli

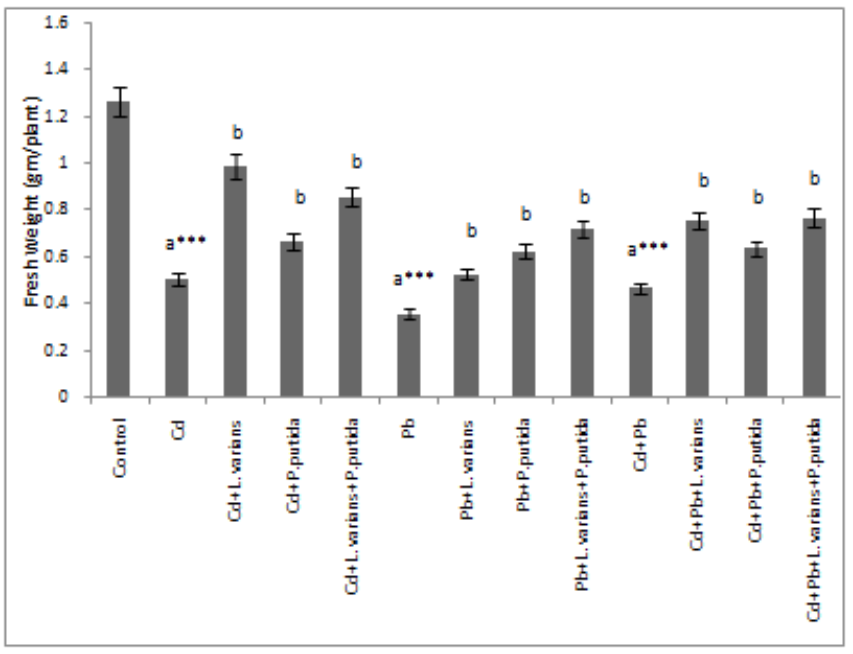

Fig. 6. Fresh weight (gm/plant) after 45 days of exposure to heavy metal enriched soil inoculating with PGPRs. Difference between control and respective heavy metal treated groups are denoted by lower case alphabet 'a'. Asteric mark $(*)$ above the bars indicate significance level. Lower case alphabet ' $\mathrm{b}$ ' indicates significant result at $p<0.05$ between heavy metal treated groups and PGPR inoculated respective heavy metal treated groups.
Fig. 8. Chlorophyll content (mg/gm tissue) of exposure to heavy metal enriched soil inoculating with PGPRs. Difference between control and respective heavy metal treated groups are denoted by lower case alphabet 'a'. Asteric mark $(*)$ above the bars indicate significance level. Lower case alphabet 'b' indicates significant result at $p<0.05$ between heavy metal treated groups and PGPR inoculated respective heavy metal treated groups. seeds. After $6 \mathrm{~h}$ of imbibitions seeds were shown in different experimental pots such as - Control, $\mathrm{Cd}, \mathrm{Cd}+L$. varians, $\mathrm{Cd}+P$. putida, $\mathrm{Cd}+L$. varians + P. putida, $\mathrm{Pb}, \mathrm{Pb}+L$. varians, $\mathrm{Pb}+P$. putida, $\mathrm{Pb}+L$. varians $+P$. putida, $\mathrm{Cd}+\mathrm{Pb}, \mathrm{Cd}+\mathrm{Pb}+L$. varians, $\mathrm{Cd}+\mathrm{Pb}+P$. putida, $\mathrm{Cd}+\mathrm{Pb}+$ L. varians $+P$. putida .

\section{Growth parameters}

After 45 days of growth, the chilli seedlings were uprooted carefully. Observation of shoot length $(\mathrm{cm})$, root length $(\mathrm{cm})$, fresh weight $(\mathrm{mg})$, dry weight (mg) and chlorophyll content $(\mathrm{mg} / \mathrm{gm}$ of tissue) were recorded. 


\section{Estimation of chlorophyll content}

Each plant material $(0.5 \mathrm{~g})$ was taken in the test tubes. Then added $10 \mathrm{ml}$ of methanol in the test tubes and kept in dark for $24 \mathrm{~h}$ (22). After this step, the supernatant solution from each test tube was taken for measurement of absorbance at 470, 652 and $665 \mathrm{~nm}$ with the help of dual beam UV-vis spectrophotometer (Model no. LI-722, Lasany, Made in India).

\section{Statistical analysis}

Standard error (SE) was calculated from triplicates of all experiments and presented as error bar in the figures $(n=3)$. Differences between the experimental groups were calculated by unpaired $t$-test. Difference between control and respective heavy metal treated groups are denoted by lower case alphabet 'a'. Asteric mark (*) above the bars indicate significant level. Lower case alphabet 'b' indicates significant result at $p<0.05$ between heavy metal treated groups and PGPR inoculated heavy metal treated groups.

\section{Results and Discussion}

Among all the isolates, two most potent heavy metal tolerant PGPR were selected for further study. Different biochemical and plant growth promoting ability are depicted the Table 1 . The results showed that the selected isolates namely $L$. varians and $P$. putida have the ability for IAA and ammonia production, and phosphate solubilisation.

In the next experiment, $L$. varians showed better survivability under all the different test soil conditions like $50 \%$ water holding capacity, flood, salinity, drought, $10 \mathrm{ppm}$ cadmium and $100 \mathrm{ppm}$ lead for 60 days (Table 2). In the case of $P$. putida, it survived for 60 days moderately under different conditions. As the selected bacterial isolates can tolerate much higher concentration of cadmium and lead, they survived under heavy metal stressed soil condition for a long day.

\section{Effect on plant growth}

The germination percentage was severely affected in the presence of heavy metals, but it was increased by the inoculation of $L$. varians, $P$. putida and combination of $L$. varians $+P$. putida under heavy metal stress (Fig. 1). In this study, $P$. putida is more potent PGPR for the enhancement of germination percentage under $\mathrm{Cd}$ and $\mathrm{Pb}$ treated condition.

Root and shoot length are very important parameters for the determination of stress condition of plants (1). Cadmium, lead and combination of Cadmium + Lead significantly reduced $(p<0.05)$ the shoot length by $23 \%, 34 \%$, $17 \%$ respectively than the shoot length of the control (Fig. 2, Photograph 1). After application of the PGPR, L. varians and P. putida significantly enhanced the growth of the test plants under heavy metal treated conditions. $L$. varians, $P$. putida and combination of $L$. varians $+P$. putida under cadmium treated conditions enhanced the shoot length by 1.41, 1.31 and 1.66 fold respectively as compare to the only Cd treatments. Under $\mathrm{Pb}$ treated conditions, L. varians, $P$. putida and combination of $L$. varians $+P$. putida enhanced the shoot length by 1.60, 1.71 and 1.72 fold respectively. Application of $\mathrm{Cd}$ with $\mathrm{Pb}$ drastically reduced the shoot length than the controlled plant whereas, PGPR inoculation nullified the stress to some extent and enhanced the shoot length by $1.43,1.39$, and 1.43 fold respectively for $L$. varians and $P$. putida and combination of $L$. varians $+P$. putida inoculated plants. Many researchers observed PGPR inoculation improved the shoot length under heavy metal contamination $(1,23,24)$.

Number of leaves apparently reduced under $\mathrm{Cd}, \mathrm{Pb}$ and combination of $\mathrm{Cd}+\mathrm{Pb}$ treated condition by $11 \%, 22 \%, 44 \%$ than the control plants. Under all heavy metal stress condition $L$. varians and $P$. putida increased the number of leaves per plant from the very beginning of seedling growth (Fig. 3). Ultimately after 45 days, $L$. varians and $L$. varians $+P$. putida inoculation slightly enhanced the number of leaves by 1.14 , 1.19 fold respectively under $\mathrm{Cd}$ stress than the only $C d$ treated condition. Similarly, $L$. varians and $L$. varians $+P$. putida enhanced the leaf number under $\mathrm{Pb}$ stressed condition. L. varians, P. putida and $L$. varians $+P$. putida increased leaf number under combined heavy metal stressed condition by $1.71,1.64$ and 1.42 fold respectively than uninoculated $\mathrm{Cd}$ and $\mathrm{Pb}$ treated plants.

Though number of leaves were not altered significantly in all the experiments, the PGPR inoculation helped to enhance the leaf area significantly $(p<0.05)$ under $\mathrm{Cd}$ and/or $\mathrm{Pb}$ exposure. The results (Fig. 4) depicted that $\mathrm{Cd}$ or $\mathrm{Pb}$ stress was inversely proportional to the leaf area but inoculation of PGPR clearly increased the average leaf area per plant under heavy metal stress condition. L. varians showed better result for leaf area enhancement under Cd stress as well as combination of $\mathrm{Cd}$ and $\mathrm{Pb}$ stress conditions.

Similar kind of results were found in case of root length where PGPRs played a key role not only to tolerate the heavy metal stress but also to promote the root length (Fig. 5, Photograph 1). Heavy metal alone or in combination reduced the root length significantly $(p<0.05)$ than the control plants whereas PGPRs nullified the heavy metal stress to increase the root length. $L$. varians, $P$. putida and combination of $L$. varians $+P$. putida enhance the root length by $1.35,1.15,1.36$ fold under $\mathrm{Cd}$ treated conditions, 1.13, 1.07, 1.45 fold under lead stress respectively than the uninoculated heavy metal stressed setups which correlated the previous works $(1,24,25)$. 

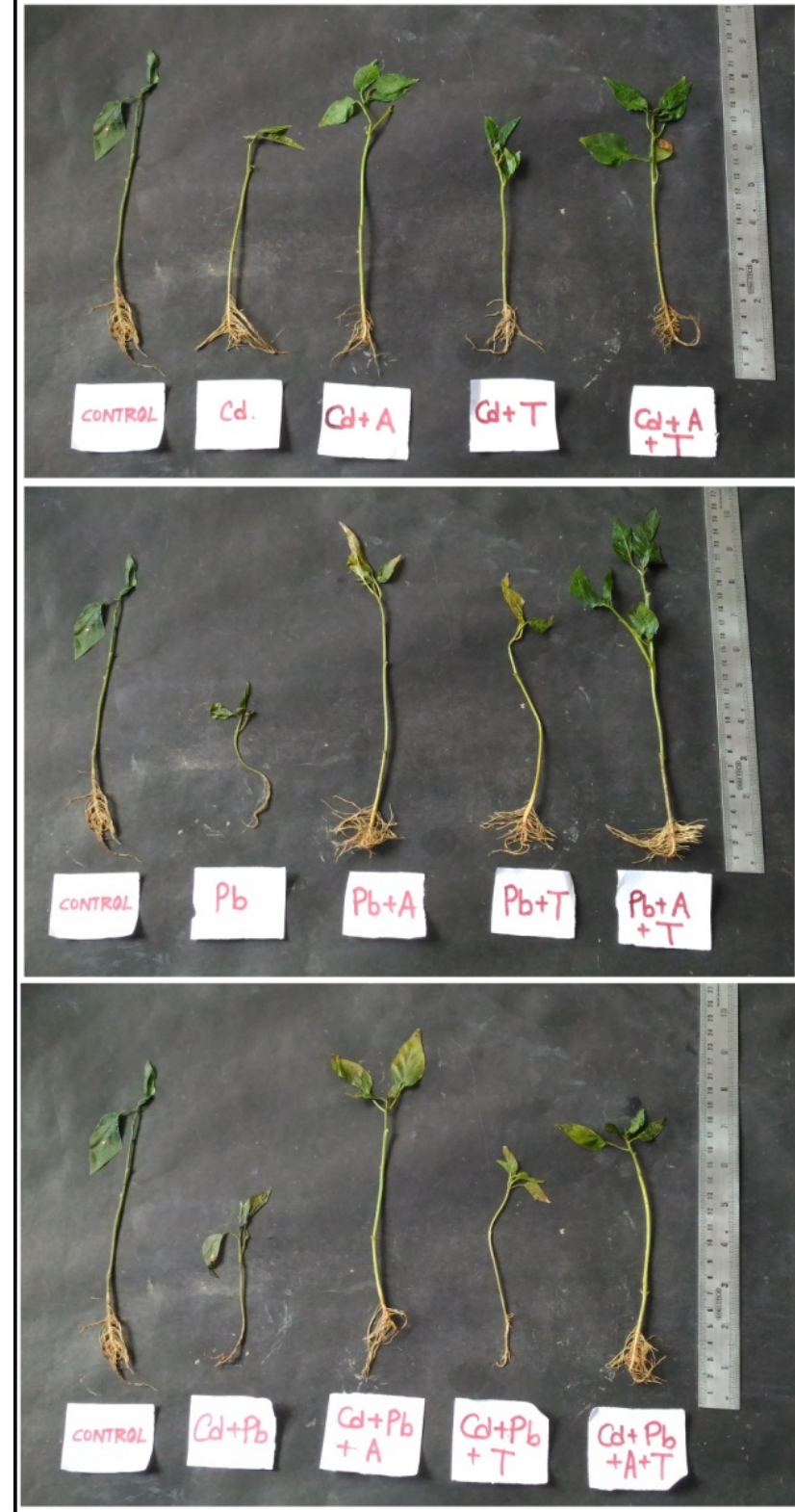

Photograph 1. Height of chili plant under different experimental condition. (A: L. varians; T: P. putida)

Very promising results were found in the case of fresh weight as PGPRs inoculation boosted up the biomass production under cadmium and lead stress (Fig. 6). The fresh weights under $\mathrm{Cd}, \mathrm{Pb}$ and combination of $\mathrm{Cd}$ and $\mathrm{Pb}$ treatment significantly $(p<0.05)$ reduced the fresh weights respectively by $59 \%, 70 \%, 62 \%$ as compared to control setup. Application of $L$. varians and $P$. putida apparently increased the growth of the test plants under heavy metal treated conditions. $L$. varians, $P$. putida and $L$. varians $+P$. putida increased the fresh weights correspondingly by 1.94, 1.31 and 1.69 fold under cadmium stress, 1.47, 1.75 and 2 fold under lead stress and 1.61, 1.36 and 1.63 fold under combined test heavy metal stressed condition than the respective heavy metal treated un-inoculated plants. It can be clearly observed that root inoculation of chilli plants with PGPR can minimize the adverse effect of heavy metal and enhanced the fresh weight. Similar kinds of result were found by different workers in various time gaps $(26,27)$. The results obtained in this study therefore is in confirmation of the earlier studies.

Dry weight of chilli plants were drastically reduced by heavy metal application but PGPR inoculation enhanced the growth of the test plant under heavy metal treated conditions. The results showed that $L$. varians, $P$. putida and combination of $L$. varians $+P$. putida increased the dry weight under all test heavy metal stress (Fig. 7). $\mathrm{Cd}$ and $\mathrm{Pb}$ tolerant PGPRs (L. varians and P. putida) produced IAA (phytohormone), which increased the nutrient accumulation by plant through better root development $(14,25)$. Moreover, $L$. varians or $P$. putida solubilise insoluble phosphate and produce ammonia that increased the growth of chilli plants under $\mathrm{Cd}$ or $\mathrm{Pb}$ exposure which support the previous works $(16,18,19)$.

\section{Effect on chlorophyll content}

Cadmium and lead drastically reduced the total chlorophyll content by $32.5 \%$ and $41.5 \%$ than the control setup. The results in this study revealed that the test heavy metals like cadmium and lead inhibited the chlorophyll biosynthesis. Whereas, application of $L$. varians and $P$. putida notably $(p<0.05)$ improved the plant growth under heavy metal treated conditions as they managed to increase the chlorophyll biosynthesis (Fig. 8). Previously, different researchers (14, 28, 29) observed heavy metal stress reduced the chlorophyll content. Moreover, heavy metal resistant or tolerant PGPR induced chlorophyll content that triggers the photosynthetic rate which helped the plants to overcome the abiotic stress (30). Heavy metal resistant PGPR alleviate $\mathrm{Cd}$ or $\mathrm{Pb}$ toxicity in plant by increasing different antioxidants $(20,24,30)$ and ultimately develop plant growth which corroborate this work.

The results of the study revealed that both the selected PGPR isolates, $L$. varians and P. putida, showed potent plant growth promoting ability under cadmium and/or lead stressed conditions.

\section{Conclusion}

This study revealed that cadmium and lead enhanced the plant growth remarkably. In addition, few rhizospheric bacteria have some plant growth promoting ability with higher dose of cadmium and lead tolerant ability. These PGPRs not only survive under cadmium and lead contaminated soil but also they exert the positive effect on plant growth promotion via direct or indirect mechanism. The cumulative effects of different plant growth promoting traits improved different morphological growth of chilli seedlings. Therefore the present study demonstrated that heavy metal tolerant PGPRs are valuable microbial resources which can be exploited to develop a sustainable agro-climatic condition and to improve the plant growth. Further study should be carried 
out for efficient application of heavy metal tolerant PGPRs for phyto-extraction and commercial purpose in the field.

\section{Authors' contribution}

AKP conducted the whole experiment, collected the data, performed statistical analysis and written up the whole manuscript. AC supported the experimental works for different plant growth parameters. CS hypothesized the paper concept, designed the experiment, supervised throughout the process.

\section{Conflict of interest}

The authors have no conflict of interest.

\section{Acknowledgements}

The authors would like to acknowledge the financial help from DST-PURSE programme to Department of Botany, University of Kalyani, from Department of Science and Technology, Government of India.

\section{References}

1. Rajkumar M, Freitas H. Effects of inoculation of plantgrowth promoting bacteria on $\mathrm{Ni}$ uptake by Indian mustard. Bioresource Technology. 2008 Jun 1;99(9):3491-8. https://doi.org/10.1016/j.biortech.2007.07.046

2. Meharg AA, Norton G, Deacon C, Williams P, Adomako EE, Price A, Zhu Y, Li G, Zhao FJ, McGrath S, Villada A. Variation in rice cadmium related to human exposure. Environmental science \& technology. 2013 May 23;47(11):5613-8. https://doi.org/10.1021/es400521h

3. Kabata-Pendias A, Pendias H. Trace elements in soils and plants, 3rd edn CRC Press. Boca Raton, FL, USA. 2001.

4. Lin YF, Aarts MG. The molecular mechanism of zinc and cadmium stress response in plants. Cellular and molecular life sciences. 2012 Oct 1;69(19):3187-206. https://doi.org/10.1007/s00018-012-1089-Z

5. TRAN TA, Popova LP. Functions and toxicity of cadmium in plants: recent advances and future prospects. Turkish Journal of Botany. 2013 Jan 24;37(1):1-3. https://doi.org/10.3906/bot-1112-16

6. Khan S, Cao Q, Zheng YM, Huang YZ, Zhu YG. Health risks of heavy metals in contaminated soils and food crops irrigated with wastewater in Beijing, China. Environmental pollution. 2008 Apr 1;152(3):686-92. https://doi.org/10.1016/j.envpol.2007.06.056

7. Clemens S, Aarts MG, Thomine S, Verbruggen N. Plant science: the key to preventing slow cadmium poisoning. Trends in plant science. 2013 Feb 1;18(2):929. https://doi.org/10.1016/j.tplants.2012.08.003

8. Abbas SZ, Rafatullah M, Ismail N, Lalung J. Isolation, identification, characterization, and evaluation of cadmium removal capacity of Enterobacter species. Journal of basic microbiology. 2014 Dec;54(12):127987. https://doi.org/10.1002/jobm.201400157
9. Hinojosa MB, Carreira JA, García-Ruíz R, Dick RP. Soil moisture pre-treatment effects on enzyme activities as indicators of heavy metal-contaminated and reclaimed soils. Soil Biology and Biochemistry. 2004;36(10):155968. https://doi.org/10.1016/j.soilbio.2004.07.003

10. Yao $\mathrm{H}, \mathrm{Xu}$ J, Huang C. Substrate utilization pattern, biomass and activity of microbial communities in a sequence of heavy metal-polluted paddy soils. Geoderma. 2003 Jul 1;115(1-2):139-48 https://doi.org/10.1016/S0016-7061(03)00083-1

11. Kloepper JW, Leong J, Teintze M, Schroth MN. Enhanced plant growth by siderophores produced by plant growth-promoting rhizobacteria. Nature. 1980 Aug;286(5776):885. https://doi.org/10.1038/286885a0

12. Khatoon N, Shafique HA, Noreen R, Sultana V, Badar R, Ehteshamul-Haque S. Role of endophytic and rhizospheric fluorescent pseudomonas associated with mungbean in suppressing the root rotting fungi of mungbeaan. Int. J. Biol. Res. 2014;2(2):115-23.

13. Glick BR. Plant growth-promoting bacteria: mechanisms and applications. Scientifica. 2012;2012. http://dx.doi.org/10.6064/2012/963401

14. Pal AK, Sengupta C. Effect of plant growth promoting rhizobacteria on early growth of Rice plant (Oryza sativa L.) under Cadmium (Cd) and Lead $(\mathrm{Pb})$ stress condition. International Journal of BioSciences \& Technology. 2016 Dec 17;9(12).

15. Treesubsuntorn C, Dhurakit P, Khaksar G, Thiravetyan P. Effect of microorganisms on reducing cadmium uptake and toxicity in rice (Oryza sativa L.). Environmental Science and Pollution Research. 2017 May 8:1-2. https://doi.org/10.1007/s11356-017-9058-6

16. Chen Y, Chao Y, Li Y, Lin Q, Bai J, Tang L, Wang S, Ying R, Qiu R. Survival strategies of the plantassociated bacterium Enterobacter sp. strain EG16 under cadmium stress. Applied and environmental microbiology. 2016 Jan 4:AEM-03689. https://doi.org/ 10.1128/AEM.03689-15

17. Gadd GM. Heavy metal accumulation by bacteria and other microorganisms. Experientia. 1990 Aug 1;46(8):834-40. https://doi.org/10.1007/BF01935534

18. Płociniczak T, Sinkkonen A, Romantschuk M, Piotrowska-Seget Z. Characterization of Enterobacter intermedius MH8b and its use for the enhancement of heavy metals uptake by Sinapis alba L. Applied soil ecology. 2013 Jan 1;63:1-7. https://doi.org/10.1016/j.apsoil.2012.09.009

19. Ahmad I, Akhtar MJ, Asghar HN, Ghafoor U, Shahid M. Differential effects of plant growth-promoting rhizobacteria on maize growth and cadmium uptake. Journal of plant growth regulation. 2016;35(2):303-15. https://doi.org/10.1007/s00344015-9534-5

20. Sarathambal C, Khankhane PJ, Gharde Y, Kumar B, Varun M, Arun S. The effect of plant growthpromoting rhizobacteria on the growth, physiology, and Cd uptake of Arundo donax L. International journal of phytoremediation. 2017 Apr 3;19(4):36070. https://doi.org/10.1080/15226514.2016.1225289

21. Wenzel WW, Lombi E, Adriano DC. Biogeochemical processes in the rhizosphere: role in phytoremediation of metal-polluted soils. In: Heavy metal stress in plants 1999 (pp. 273-303). Springer, Berlin, Heidelberg. https://doi.org/10.1007/978-3-662$\underline{07745-0 \quad 13}$ 
22. Porra RJ, Thompson WA, Kriedemann PE. Determination of accurate extinction coefficients and simultaneous equations for assaying chlorophylls $\mathrm{a}$ and $\mathrm{b}$ extracted with four different solvents: verification of the concentration of chlorophyll standards by atomic absorption spectroscopy. Biochimica et Biophysica Acta (BBA)Bioenergetics. 1989 Aug 1;975(3):384-94. https://doi.org/10.1016/S0005-2728(89)80347-0

23. Chmielewska-Bak J, Lefèvre I, Lutts S, Kulik A, Deckert J. Effect of cobalt chloride on soybean seedlings subjected to cadmium stress. Acta Societatis Botanicorum Poloniae. 2014;83(3). DOI $\underline{10.5586 / a s b p .2014 .027}$

24. Pramanik K, Mitra S, Sarkar A, Soren T, Maiti TK. Characterization of cadmium-resistant Klebsiella pneumoniae MCC 3091 promoted rice seedling growth by alleviating phytotoxicity of cadmium. Environmental Science and Pollution Research. 2017 Nov 1;24(31):24419-37 https://doi.org/10.1007/s11356-017-0033-z

25. Belimov AA, Dietz KJ. Effect of associative bacteria on element composition of barley seedlings grown in solution culture at toxic cadmium concentrations. Microbiological research. 2000 Jan 1;155(2):113-21. https://doi.org/10.1016/S0944-5013(00)80046-4

26. Safronova VI, Stepanok VV, Engqvist GL, Alekseyev YV, Belimov AA. Root-associated bacteria containing 1-aminocyclopropane-1-carboxylate deaminase improve growth and nutrient uptake by pea genotypes cultivated in cadmium supplemented soil. Biology and Fertility of Soils. 2006 Feb 1;42(3):26772. https://doi.org/10.1007/s00374-005-0024-y

27. Saleem M, Arshad M, Hussain S, Bhatti AS. Perspective of plant growth promoting rhizobacteria (PGPR) containing ACC deaminase in stress agriculture. Journal of industrial microbiology \& biotechnology. 2007;34(10):635-48. https://doi.org/10.1007/s10295-0070240-6

28. Sun Y, Zhou Q, Diao C. Effects of cadmium and arsenic on growth and metal accumulation of $\mathrm{Cd}$ hyperaccumulator Solanum nigrum L. Bioresource Technology. 2008 Mar 1;99(5):1103-10. https://doi.org/10.1016/j.biortech.2007.02.035

29. Sheng XF, Xia JJ. Improvement of rape (Brassica napus) plant growth and cadmium uptake by cadmium-resistant bacteria. Chemosphere. 2006 Aug 1;64(6):1036-42.

https://doi.org/10.1016/j.chemosphere.2006.01.051

30. Haneef I, Faizan S, Perveen R, Kausar S. Impact of biofertilizers and different levels of cadmium on the growth, biochemical contents and lipid peroxidation of Plantago ovata Forsk. Saudi journal of biological sciences. $\quad 2014 \quad$ Sep 1;21(4):305-10. https://doi.org/10.1016/j.sjbs.2013.12.005 